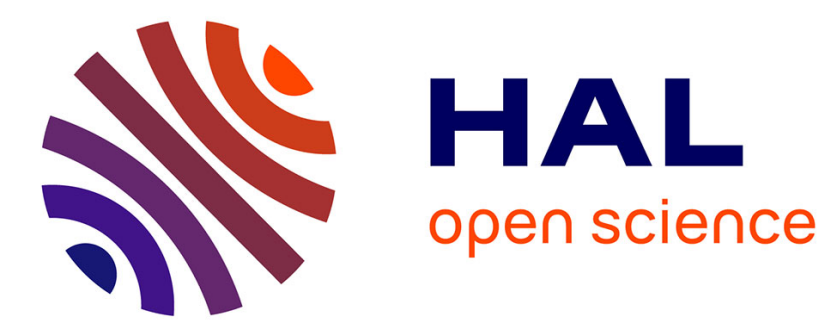

\title{
Micromechanical Approach of the Fatigue Behavior in a Superelastic Single Crystal
}

E. Patoor, N. Siredey, A. Eberhardt, M. Berveiller

\section{To cite this version:}

E. Patoor, N. Siredey, A. Eberhardt, M. Berveiller. Micromechanical Approach of the Fatigue Behavior in a Superelastic Single Crystal. Journal de Physique IV Proceedings, 1995, 05 (C8), pp.C8-227-C8232. 10.1051/jp4:1995831. jpa-00254080

\section{HAL Id: jpa-00254080 https://hal.science/jpa-00254080}

Submitted on 1 Jan 1995

HAL is a multi-disciplinary open access archive for the deposit and dissemination of scientific research documents, whether they are published or not. The documents may come from teaching and research institutions in France or abroad, or from public or private research centers.
L'archive ouverte pluridisciplinaire HAL, est destinée au dépôt et à la diffusion de documents scientifiques de niveau recherche, publiés ou non, émanant des établissements d'enseignement et de recherche français ou étrangers, des laboratoires publics ou privés. 


\title{
Micromechanical Approach of the Fatigue Behavior in a Superelastic Single Crystal
}

\author{
E. Patoor, N. Siredey, A. Eberhardt and M. Berveiller \\ Laboratoire de Physique et Mécanique des Matériaux, URA 1215 du CNRS, Institut Supérieur de Génie \\ Mécanique et Productique, Université de Metz, Ile du Saulcy, 57045 Metz cedex, France
}

\begin{abstract}
Mechanical cycling of superelastic alloys leads to significant change in their observed behavior. Critical stress needed to induce the martensitic transformation is reduced while the tangent transformation modulus is increased. Microstructural observations have shown that a mechanical cycling produced a strongly oriented pattern of dislocations. This dislocation network is associated to an internal stress field. It seems reasonable to relate this internal stress field to the observed evolution of the mechanical response. This is phenomenologically performed in this work considering the thermodynamical potential associated to the martensitic transformation of a single crystal of parent phase in presence of a microstructure of defects. Evolutions of the microstructural state are defined using the volume fraction associated to the variant of martensite and additional volume fractions of defects related to the dislocation pattern. Results such obtained well-captured experimental observations.
\end{abstract}

\section{INTRODUCTION}

Since the 80's lots of attentions are given to model the superelastic effect observed in shape memory alloys. At the exception of Bourbon et al. [1] and Tanaka et al. [2] all these works consider such effect as a perfect one suffering no evolution during a cyclic loading-unloading path. Unfortunately fatigue phenomena strongly affect the real superelastic behavior [3]. Such influence is related to a production of defects during the martensitic transformation and to interaction between these defects and the transformation itself [4]. This gives a complex problem where description of the martensitic microstructure alone is no longer enough. To deal with this problem, microstructural aspects related to the defects must be accounted and interaction mechanisms between defects and phase change are to be describe. A macroscopic point of view like in $[1,2]$ is not able to deal accurately with such problem. Micromechanical analysis developed in mechanics of material since many years has to be applied. This contribution constitutes a first attempt in that way. In this work only interaction between the transformation and a microstructure of defects is taken into account. Physical mechanisms at the origin of the production of new defects during the thermoelastic martensitic transformation are not describe. In order to avoid complexity, interaction between a single variant of martensite and defects characterized by a plastic deformation in the parent phase is modeled. This corresponds to the fatigue behavior of single crystal for uniaxial tensile test.

\section{EXPERIMENTAL DATA OF LITERATURE}

Many experiments concerning mechanical cycling of shape memory alloy single crystals have been realized by Sade and coworkers [3-9] on $\mathrm{Cu}-\mathrm{Zn}-\mathrm{Al}$ material.

From the mechanical point of view they observed that when the number of cycles increases, tensile $\sigma-\varepsilon$ curve changes : stress at the start of the martensitic transformation is reduced, while the slope of the curve increases as presented in figure 1 . In addition, an increase in the hysteresis size is observed : more and more energy is dissipated at each cycle. This is true for the first cycles; for further cycling a saturation occurs for the hardening of the $\sigma-\varepsilon$ curves as well as for hysteresis. Analysis of the behavior emphasizes that response to mechanical cycling does not really depend on tensile test orientation : when normalizing the behavior by using resolved shear stress, authors show that the results for the various orientations are similar. Instead of those temperature plays an important role : because the difference $\Delta \mathrm{T}$ between the test temperature $\mathrm{T}$ and $\mathrm{M}_{S}$, 
temperature of the beginning of martensitic transformation without applied stress, is a crucial parameter [6,7], but also because test temperature itself for given $\Delta T$ has an influence [3]. For a given $\Delta T$ and a given number of cycles, the slope of $\sigma-\varepsilon$ curve is higher at low temperature than for higher temperatures.

The authors compared mechanical behavior changes with metallographic ones. They observed that, as the number of cycles increases, more defects related to martensitic transformation are created. Two kinds of defects are found in the matrix after cycling : defects lying in planes corresponding to the habit planes of martensite and defects lying on a (110) $\beta$ plane which becomes after martensitic transformation the basal close packed plane of the $18 \mathrm{R}$ - martensite $[3,4,5,8,10]$. Rios-Jara et al. [11] mentioned the existence of pairs of dislocations in matrix. They attribute them to the dissociation during transformation of a unique initial dislocation in martensite. Finally, it is noted that types of defects created by cycling could be different according to tensile or compressive tests. For example, residual martensite after unloading can exist after compressive cycling whereas no residual martensite is detected in tensile tests $[7,8]$.

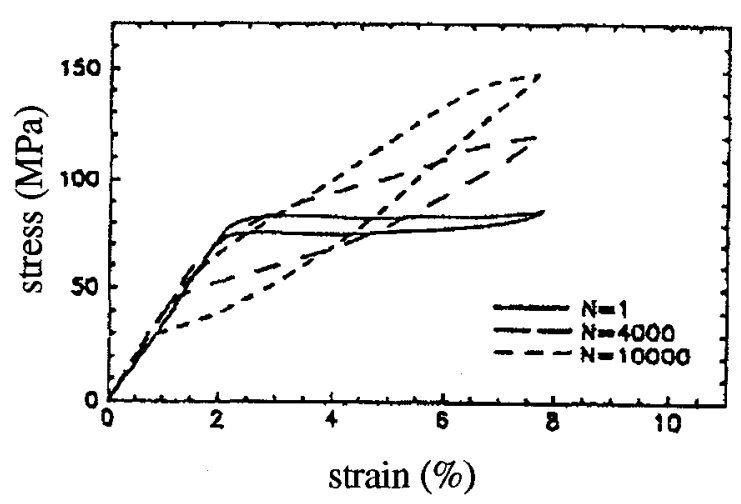

Figure 1 : experimental stress-strain curves obtained on sample labelled "d1" by Malarria and Sade [3] when $N$, the number of cycling varies.

\section{MODELIZATION}

\subsection{Microstructural description}

Uniaxial tensile test induces a single variant of martensite, the best oriented according to the applied stress. In that case, cyclic loading allows to study interaction effects between one variant of martensite and the pattern of defects produced by its growing. Considering these defects are dislocations we describe the parent phase as a homogeneous medium (without any plastic strain) prior any cyclic loading. An increasing amount of inhomogeneous plastic strain is used to described the microstructural evolution with the number of cycles. In such a description a close relation does exist between the volume fraction of these defects and the number of cycles. Determination of this relation is not in the scope of this presentation. After the first cycle, further transformation occurs in presence of this microstructure of defects. Observations have shown that some interactions take place between the phase interface and dislocations. The Burger's vector is changed and the interface drags some partial [12]. That is taken into account in a simplified way considering a two phase mixture constituted by a parent phase of volume $V_{A}$ and a product phase of volume $V_{M}$, each of them including a certain amount of defects. Volume $V_{A}$ of parent phase is composed with a volume $V_{P A}$ of defects having a plastic strain $\varepsilon^{\mathrm{PA}}$ and a volume $\mathrm{V}_{\mathrm{AA}}\left(\mathrm{V}_{\mathrm{A}}=\mathrm{V}_{\mathrm{PA}}+\mathrm{V}_{\mathrm{AA}}\right)$ free of inelastic strain. Product phase contains a volume $V_{P M}$ of defects where a plastic strain equal to $\varepsilon^{\mathrm{PM}}$ (with $\varepsilon^{\mathrm{PM}} \neq \varepsilon^{\mathrm{PA}}$ ) and a transformation strain $\varepsilon^{T}$ takes place, and a volume $V_{M M}$ where $\varepsilon^{T}$ is the only inelastic strain $\left(V_{M}=V_{P M}+V_{M M}\right)$ (fig. 2). To derive the mechanical behavior associated to such a microstructure kinematical and thermodynamical analyses are performed.

\subsection{Kinematical analysis}

In such a microstructure, the local strain field is composed by elastic, thermal, plastic and transformation parts. Considering only one variant of martensite one may assume the transformation strain takes a uniform 
value $\varepsilon^{T}$ inside the martensitic domain $V_{M}\left(\varepsilon^{T}(r)=\varepsilon^{T} \theta^{T}(r)\right.$ with $\theta^{T}(r)=1$ if $r \in V_{M}$ and $\theta^{T}(r)=0$ if $\left.r \notin V_{M}\right)$. Same assumptions are made for the plastic strains occurring in volume $V_{P M}$ and $V_{P A}$. The expression of the plastic strain field is then given by:

$$
\varepsilon \mathrm{P}(\mathrm{r})=\varepsilon^{\mathrm{PA}} \theta^{\mathrm{PA}}(\mathrm{r})+\varepsilon^{\mathrm{PM}} \theta^{\mathrm{PM}}(\mathrm{r})
$$

where $\theta^{\mathrm{PA}}(\mathrm{r})$ (resp. ${ }^{\mathrm{PM}}(\mathrm{r})$ ) is the indicator function for volume $\mathrm{V}_{\mathrm{PA}}$ (resp. $\mathrm{V}_{\mathrm{PM}}$ ). In small strain approximation, overall strain $\mathrm{E}$ is obtained from :

$$
E_{i j}=\frac{\varepsilon_{i j}^{P A}}{V} \int_{V} \theta^{P A}(r) d V+\frac{\varepsilon_{i j}^{P M}}{V} \int_{v} \theta^{P M}(r) d V+\frac{\varepsilon_{i j}^{T}}{V} \int_{V} \theta^{T}(r) d V+\frac{1}{V} \int_{v} \varepsilon_{i j}^{e}(r) d V+\frac{1}{V} \int_{V} \varepsilon_{i j}^{\text {th }}(r) d V
$$

Assuming elastic constants and thermal expansion factor are uniform inside the two phases turns relation (2) into :

$$
\begin{aligned}
E_{i j} & =E_{i j}^{e}+E_{i j}^{t h}+\varepsilon_{i j}^{T} \frac{V_{M}}{V}+\varepsilon_{i j}^{P A} \frac{V_{P A}}{V_{A}} \frac{V_{A}}{V}+\varepsilon_{i j}^{P M} \frac{V_{P M}}{V_{M}} \frac{V_{M}}{V} \\
& =E_{i j}^{e}+E_{i j}^{t h}+\varepsilon_{i j}^{T} f+\varepsilon_{i j}^{P A} F^{A}(1-f)+\varepsilon_{i j}^{P M} F^{M} f
\end{aligned}
$$

denoting by $F^{A}=\frac{V_{P A}}{V_{A}}$ and $F^{M}=\frac{V_{P M}}{V_{M}}$ the volume fractions of defects in each phase.

From a kinematical point of view the two last contributions in (3) are negligible in regard of the transformation strain but they are source of an internal stress field that play a large role on the free energy.

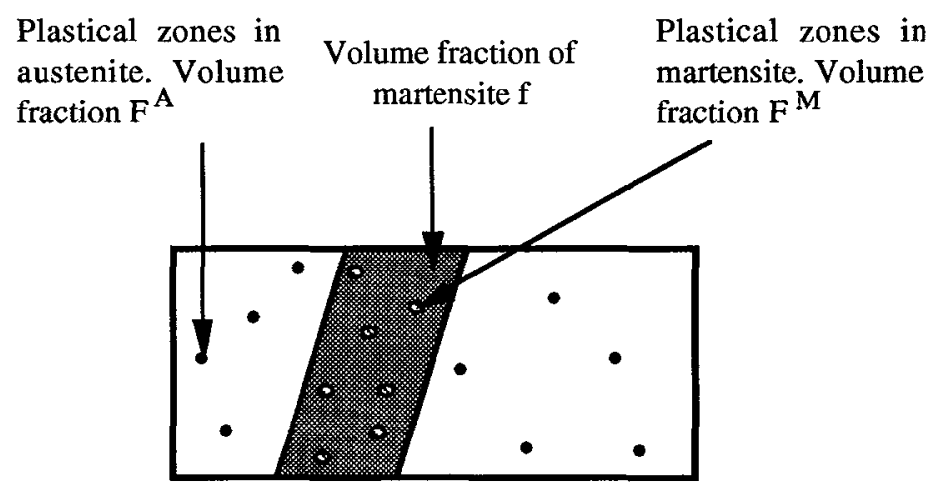

Figure 2 : Microstructural aspects used to described the fatigue behavior of single crystal. Defects domains plastically deformed are considered in a two-phases mixture.

\subsection{Thermodynamical potential in presence of defects}

Like for a domain free of defect, complementary free energy is composed by a chemical energy, an elastic energy, interfacial energy (that is negligible in shape memory alloys) and potential energy due to the loading system. Complementary free energy is a function of control parameters (applied stress $\Sigma$ and temperature $T$ ) and sets of internal variables related to the transformation strain field $\left\{\varepsilon^{T}\right\}$ but also to the pattern of defects originated from the cycling loading $\{\varepsilon \mathrm{P}\}$. According to [13] it comes : 


$$
\begin{gathered}
\Psi\left(\Sigma_{i j}, T,\left\{\varepsilon^{T}\right\},\left\{\varepsilon^{P}\right\}\right)=\frac{1}{2} \Sigma_{i j} S_{i j k l} \Sigma_{k l}-B\left(T-T_{0}\right) f+\Sigma_{i j}\left(\varepsilon_{i j}^{T} f+\varepsilon_{i j}^{P A} F^{A}(1-f)+\varepsilon_{i j}^{P M} F^{M} f\right) \\
+\frac{1}{2 V} \int_{v} \tau_{i j}(r) \varepsilon_{i j}^{i n}(r) d V
\end{gathered}
$$

where $\tau(\mathbf{r})$ denotes the internal stress field related to the inelastic strain field $\varepsilon^{\text {in }}$. This strain field is composed by the transformation strain $\left\{\varepsilon^{\mathrm{T}}\right\}$ and by plastic contributions ( $\varepsilon^{\mathrm{PA}}$ and $\varepsilon^{\mathrm{PM}}$ ). Interaction energy due to incompatibilities in the inelastic strain field can be decomposed into several contributions having different physical origin. Since $\varepsilon^{\text {in }}$ is piecewise uniform, the integral in (4) related with internal stress may be written :

$W_{\text {int }}=\frac{1}{2 V} \int_{V} \tau_{i j}(r) \varepsilon_{i j}^{i n}(r) d V=\frac{1}{2 V} V_{P A} \varepsilon_{i j}^{P A} \bar{\tau}_{i j}^{P A}+\frac{1}{2 V} V_{M M} \varepsilon_{i j}^{T} \bar{\tau}_{i j}^{M M}+\frac{1}{2 V} V_{P M}\left(\varepsilon_{i j}^{P M}+\varepsilon_{i j}^{T}\right) \bar{\tau}_{i j}^{P M}$

where $\quad \bar{\tau}_{\mathrm{ij}}^{\mathrm{X}}=\frac{1}{\mathrm{~V}_{\mathrm{x}}} \int_{\mathrm{Vx}} \tau_{\mathrm{ij}}(\mathrm{r}) \mathrm{dV} \quad$ (label $\mathrm{x}$ is referring to volumes $\mathrm{V}_{\mathrm{PM}}, \mathrm{V}_{\mathrm{PA}}$ and $\mathrm{V}_{\mathrm{AA}}$ )

Using the relations: $\frac{V_{P A}}{V}=\frac{V_{P A}}{V_{A}} \frac{V_{A}}{V} ; \frac{V_{M M}}{V}=\frac{V_{M M}}{V_{M}} \frac{V_{M}}{V}$ and $\frac{V_{P M}}{V}=\frac{V_{P M}}{V_{M}} \frac{V_{M}}{V}$, equations (5) gives:

$$
W_{i n t}=\frac{1}{2}(1-f) F^{A} \cdot \varepsilon_{i j}^{P A} \bar{\tau}_{i j}^{P A}+\frac{1}{2} f\left(1-F^{M}\right) \varepsilon_{i j}^{T} \bar{\tau}_{i j}^{M M}+\frac{1}{2} f F^{M}\left(\varepsilon_{i j}^{P M}+\varepsilon_{i j}^{T}\right) \bar{\tau}_{i j}^{P M}
$$

The austenite-martensite interface is assumed to be a habit plane so that $\left\{\varepsilon^{\mathrm{T}}\right\}$ does not produce internal stress. For dilute plastic strain and random spherical shape of plastic zones, Eshelby's inclusion problem may be used for evaluating stresses $\bar{\tau}^{x}$.

$$
\begin{aligned}
& \bar{\tau}_{i \mathrm{j}}^{\mathrm{PA}}=-\mu \quad \varepsilon_{\mathrm{ij}}^{\mathrm{PA}} \\
& \bar{\tau}_{\mathrm{ij}}^{\mathrm{MM}}=-\mu \quad \varepsilon_{\mathrm{ij}}^{\mathrm{PM}} \\
& \bar{\tau}_{\mathrm{ij}}^{\mathrm{PM}}=\mu \mathrm{F}^{\mathrm{M}} \varepsilon_{\mathrm{ij}}^{\mathrm{PA}}
\end{aligned}
$$

So that interaction energy (6) comes :

$$
W_{i n t}=-\frac{\mu}{2}(1-f) F^{A} \varepsilon_{i j}^{P A} \varepsilon_{i j}^{P A}-\frac{\mu}{2} f F^{M} \varepsilon_{i j}^{P M} \varepsilon_{i j}^{P M}
$$

The fraction of plastic zones inside martensite could be considered as proportional to the fraction of plastic zones in austenite. As the number of defects increases because of martensitic transformation, $\mathrm{F}^{\mathrm{M}}$ is also assumed to be dependent on $\mathrm{f}$. Mixing these two assumptions leads to propose the following expression for relating $\mathrm{F}^{\mathrm{M}}$ to $\mathrm{f}$ :

$$
F^{M}=F^{A}(1+a f)
$$

where the parameter $a$ is an unknown coefficient. Finally, for small values of $\mathrm{F}^{\mathrm{M}}$ and $\mathrm{F}^{\mathrm{A}}, \Psi$ becomes :

$$
\Psi\left(\Sigma_{i j}, T,\left\{\varepsilon^{T}\right\},\left\{\varepsilon^{P}\right\}\right)=\frac{1}{2} \Sigma_{i j} S_{i j k l} \Sigma_{k l}-B\left(T-T_{0}\right) f-\frac{\mu}{2}(1-f) F^{A} \varepsilon_{i j}^{P A} \varepsilon_{i j}^{P A}-\frac{\mu}{2} f(1+a f) F^{A} \varepsilon_{i j}^{P M} \varepsilon_{i j}^{P M}
$$

Derivating $\Psi$ with respect to $f$ allows to obtain the expression of the driving force $F_{f}$ for transformation. 


$$
\frac{\partial \Psi}{\partial f}=F_{f}=-B\left(T-T_{0}\right)+\Sigma_{i j} \varepsilon_{i j}^{T}+\frac{\mu}{2} F^{A}\left(\varepsilon_{i j}^{P A} \varepsilon_{i j}^{P A}-\varepsilon_{i j}^{P M} \varepsilon_{i j}^{P M}\right)-\mu \text { af } F^{A} \varepsilon_{i j}^{P M} \varepsilon_{i j}^{P M}
$$

Dissipative aspect is accounted, considering transformation takes place on loading, when driving force (11) reaches a critical value $F_{c}$. Application to tensile test condition allows to transformed equation (11) to a scalar one. In this case the stress necessary to induce the transformation is expressed by :

$$
\Sigma=\frac{F_{c}+B\left(T-T_{0}\right)+\frac{\mu}{2} F^{A}\left(\left(\varepsilon^{P M}\right)^{2}-\left(\varepsilon^{P A}\right)^{2}\right)+f \mu a F^{A}\left(\varepsilon^{P M}\right)^{2}}{\varepsilon^{T}}
$$

Same analysis is used for unloading condition replacing $F_{c}$ by $-F_{c}$. This gives a simpler description for the hysteretic behavior in superelasticity. Results obtained in that way with an evolution of the fatigue parameters are presented in the next section.

\section{RESULTS}

\subsection{Analysis of the model}

Comparing to the expression for $\Sigma$ in classical analysis of the stress-assisted martensitic transformation, two new terms appear. The change of behavior with cycling will be represented by the increase of number of defects in matrix $F^{A}$ as metallographically observed by Sade and coworkers. So, the first term of the stress, that is to say $\frac{\mu}{2} F^{A}\left(\left(\varepsilon^{P M}\right)^{2}-\left(\varepsilon^{P A}\right)^{2}\right)$, produces a change in the stress of the beginning of martensitic transformation as observed experimentally. This change in the value of the stress corresponds to a decrease if defect areas in martensite are less deformed than in matrix. This would then be realistic if one considers that martensite should relax matrix energy when nucleating and growing. The second term $f \mu a F^{A}\left(\varepsilon^{P M}\right)^{2}$ is responsible for hardening of the $\Sigma$ - $\varepsilon$ curve. This could be explain considering that the austenite-martensite interface has to pass through the pattern of defects previously formed inside the matrix. This requires an additional energy and then an increase of the stress.

\subsection{Comparison with experiments}

The model is applied to Cu-based single crystal and compared to the experimental results of Malarria and Sade [3] for the sample denoted in their paper "d1". Experimental conditions are $\mathrm{T}_{\exp }=-174^{\circ} \mathrm{C}, \Delta \mathrm{T}=30^{\circ} \mathrm{C}$ and orientation of the tensile test close from $(0.9500 .29)$. Elastic constants are taken equal to $E=100,000 \mathrm{MPa}$ and $v=0.3$. Parameter $B$ used in thermodynamical potential (4) is $B=0.2 \mathrm{~J} \cdot \mathrm{K}^{-1}[13]$.

As the orientation of the tensile axis compared to the sample is different from (001), the transformation deformation $\varepsilon^{\mathrm{T}}$ is smaller than $10 \%$. It is taken equal to $8.5 \%$. Parameter a being unknown, the simplest value is taken : $a$ is equalized to unity. The width of hysteresis is determined from the value of $F_{c}$. For a first approximation, $\mathrm{F}_{\mathrm{c}}$ is kept constant according to cycling and remained at the value corresponding to the experimental width of the first cycle (matrix almost without defects), $F_{c}$ is taken around $1 \mathrm{~J} \cdot \mathrm{m}^{-3}$.

Figure 3 presents the results of the calculation. To modelize the cycling, only fraction of defects in matrix $\mathrm{F}^{\mathrm{A}}$ varies when number of cycles increases. This model agrees with experimental results if the values for $\varepsilon^{\mathrm{PM}}$ and $\varepsilon^{\mathrm{PA}}$ are respectively $35 \%$ and $42 \%$. These are reasonable values in the sense that one expects highly deformed areas. The calculation shows that only very little amount of defects is needed to reproduce the change in mechanical behavior of the samples.

\section{DISCUSSION}

In the present model two scalar parameters ( $a$ and $F^{A}$ ) and two tensorial ones $\left(\varepsilon^{\mathrm{PM}}\right.$ and $\varepsilon^{\mathrm{PA}}$ ) are used to accounted with the cyclic behavior of superelastic single crystal. In these materials, considerations about 
fatigue mechanism (interaction between a single interphase interface with a dislocations pattern) allow to give a physical meaning to these parameters.

Volume fraction $\mathrm{F}^{\mathrm{A}}$ describes the number of defects remaining in the matrix after unloading. This parameter increases with the number of cycles, but such evolution is not study in this work.

Parameter a is used to describe how a defect of the parent phase is transformed into a defect of the product phase. As there is very little amount of defects, one could expect that there is no interaction between defects areas and so, $\mathrm{a}$ is independent to $\mathrm{F}^{\mathrm{A}}$. It is also assumed that this interaction mechanism suffers no evolution with the progress of the transformation and during the cycling process, thus a is independent to the volume fraction of martensite and to the number of cycles.

Plastic deformations deformations $\varepsilon^{\mathrm{PM}}$ and $\varepsilon^{\mathrm{PA}}$ are supposed to be independent on $\mathrm{f}$ and $\mathrm{F}^{\mathrm{A}}$. Relation that does exist between $\varepsilon^{\mathrm{PM}}$ and $\varepsilon^{\mathrm{PA}}$ is not discussed in this work, parameter $\mathrm{a}$ is then the only parameter used to account with the interaction mechanisms occurring during the phase change.

Sade and coworkers have observed that experimental conditions such as orientation of the tensile axis and temperature play a large role in the fatigue behavior. The interaction mechanism can be assume to be related to the mobility of dislocations and to annihilation phenomenon and then parameter a is expected to be temperature dependent. On the same way, orientation of the interface must have a large influence on this interaction. So this parameter is also expected to be dependent on the solicitation axis orientation. These evolutions have no to be established from analysis of experimental data.

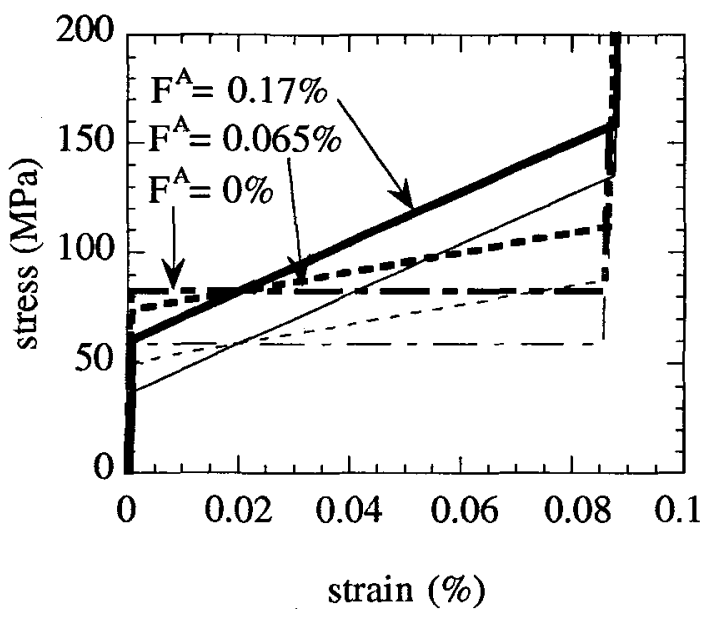

Figure 3 : stress-strain curves obtained by the present model for different values of $\mathrm{F}^{\mathrm{A}}$.

\section{References}

[1] Bourbon G., Lexcellent C, Leclercq S, this conference.

[2] Tanaka K, Nishimura F, Hayashi T, Tohushi H, Lexcellent C, Mechanics of Materials 19 (1995) 281292

[3] Malarria J. and Sade M., Scripta Met. et Mater. 30 (1994) 241-246

[4] Sade M., Rapacioli R., Ahlers M., Acta Metall. 33 (1985) 487-497

[5] Sade M., Ahlers M., Scripta Met. 19 (1985) 425-430

[6] Sade M., Hornbogen E., Z. Metallkde 79 (1988) 782-786

[7] Picornell C., Sade M., Cesari E., Met. Trans. A, 25A (1994) 687-695

[8] Sade M., Lovey F.C., Ahlers M., ICOMAT'86, Nara, Japan (1986) 934-936

[9] Picornell C., Sade M., Cesari E., Scripta Met. 23 (1989) 371-376

[10] Sakamoto H., Shimizu K., Otsuka K., Trans. JM 22 (1981) 579-587

[11] Rios-Jara D., Morin M., Esnouf C., Guénin G., Scripta Met. 19 (1985), 441-446

[12] Lovey F.C., Amengual A., Torra V., Ahlers M., Phil. Mag. A, 61 (1990) pp. 159-165

[13] Patoor E., Eberhardt A., Berveiller M., Proc. ASME WAM '94, Chicago, IL (USA) (1994), AMDVol. 189 / PVD- Vol. 292, pp. 23-37 